\title{
New Technology for Increasing Through-Life Reliability of Ceramics Components Using Self-Crack-Healing Ability
}

\author{
Kotoji Ando, Koji Takahashi, Wataru Nakao, Toshio Osada, and Kae Iwanaka \\ Department of Energy and Chemical Engineering, Yokohama National University, 79-5 Tokiwadai, Hodogaya, \\ Yokohama 240-8501, Japan \\ Correspondence should be addressed to Kotoji Ando; andokoto@ynu.ac.jp
}

Received 15 March 2013; Accepted 8 May 2013

Academic Editor: Fariborz Tavangarian

Copyright (C) 2013 Kotoji Ando et al. This is an open access article distributed under the Creative Commons Attribution License, which permits unrestricted use, distribution, and reproduction in any medium, provided the original work is properly cited.

\begin{abstract}
Structural ceramics are superior to metallic materials in terms of their high-temperature strengths and critical heat proof temperatures. However, compared to metallic materials, ceramics exhibit lower fracture toughness, so they are more sensitive to flaws such as pores and cracks. The shortness considerably decreases the component reliability. To overcome the shortness, in this study, special attention is paid to structural ceramics with self-crack-healing ability. There are several advantages for using a material with self-crack-healing ability. (1) After an efficient machine operation, the materials are able to self-heal the cracks introduced by the machining. (2) The materials are able to self-heal the cracks introduced during service and recover the strength completely at healing temperature. However, ways of organizing the available knowledge to increase the through-life reliability of ceramics components have not been extensively studied. The authors propose a new concept and the corresponding flowchart. This new concept is a promising technique for increasing the through-life reliability of ceramics components with excellent self-crack-healing ability.
\end{abstract}

\section{Introduction}

Structural ceramics are superior to metallic materials in terms of their high-temperature strengths and critical heat-proof temperatures. Structural ceramics are leading candidate materials for high-temperature applications such as components of gas turbines. However, compared to metallic materials, ceramics exhibit lower fracture toughness, so they are more sensitive to flaws such as pores and cracks. The reliability of structural ceramics in machinery is therefore limited by the following three problems. (1) Cracks occur during machining (e.g., grinding and polishing), considerably decreasing the component reliability. In order to prevent this, precise polishing is required in the final stage, which is timeconsuming and lowers the fabrication efficiency and raises the fabrication cost. (2) In particular, cracks of depth about $10-30 \mu \mathrm{m}$ affect the reliability. Nondestructive inspection technologies for detecting cracks of depth $10-30 \mu \mathrm{m}$ have yet to be developed. (3) Cracks may occur for various reasons in components during their use at high temperatures.

To overcome the above problems, in this study, special attention is paid to structural ceramics with self-crack-healing ability. There are several advantages to using a material that can heal its own surface cracks. First of all, if the selfhealing of the surface crack is carried out after an efficient machine operation is performed, the fabrication efficiency is greatly improved and the fabrication cost is lowered. Furthermore, the healing of all surface cracks greatly improves reliability. Finally, the healing of a crack that occurs during service is highly advantageous, especially if the self-crack-healing ability allows the material to completely recover its original strength.

In this paper, a new methodology is proposed for guaranteeing the through-life reliability of ceramics components, based on studies by the authors of materials with excellent self-crack-healing ability, proof test theory, and self-crackhealing behavior during service under low oxygen partial pressure $\left(P_{\mathrm{O}_{2}}\right)[1,2]$.

\section{Flowchart of Through-Life Reliability Managements of Ceramics Components with Excellent Self-Crack-Healing Ability}

Recently, many useful studies of ceramics with self-crackhealing ability have been performed $[1,2]$. However, ways of 
organizing the available knowledge to increase the throughlife reliability of ceramics components have not been extensively studied. The authors propose a new concept, and the corresponding flowchart is shown in Figure 1. This new concept is a promising technique for increasing the through-life reliability of ceramics components with excellent self-crackhealing ability.

Heavily Machined Components. This is related to process no. (1) in Figure 1. After the sintering of ceramics, machining such as grinding is carried out to give the required form. In general, long and deep cracks can be introduced by machining, as shown in Figure 2 [3]. These cracks considerably reduce the strength and reliability of the components. In the case of traditional technology, after the high-performance machining process, final machining processes such as polishing and lapping are performed to remove unacceptable flaws. Although these processes are generally very costly and timeconsuming, they cannot eliminate minute cracks completely. It is anticipated that substituting the crack-healing process for the final machining processes will lead to economical manufacturing of ceramics components with high reliability.

Service Temperature. This is related to process no. (2) in Figure 1.

In Figure 1, $T_{s}$ is the service temperature, and $T_{\text {csch }}$ is the critical lower temperature for self-crack-healing. If $T_{s}$ is higher than $T_{\text {csch }}$, the material is able to self-heal cracks introduced during service and completely recover its strength, as shown in Figure 4 [4]. Consequently, the fatigue limit is almost equal to the minimum fracture strength, as shown in Figure 11 [5].

If $T_{s}$ is lower than $T_{\text {csch }}$, the material is not able to self-heal cracks introduced during service. To increase the reliability of ceramics components, compressive residual stress should therefore be introduced by shot peening (SP); this method is very useful, as shown in Figures 13, 14, and 15 [6].

Lapping. This is related to process no. (3) in Figure 1. Polishing and lapping are performed as final machining processes. These processes have two purposes: (a) reducing the roughness induced by heavy machining and (b) removing unacceptable flaws. Although these processes are generally very costly, they cannot eliminate minute cracks, as mentioned in Section 4.1 .

When $T_{s}$ is higher than $T_{\text {csch }}$, if necessary, slight lapping should be carried out to reduce the roughness. When $T_{s}$ is lower than $T_{\text {csch }}$, heavy lapping should be carried out to eliminate cracks introduced by machining and also to prevent chipping by SP.

Shot Peening. This is related to process no. (4) in Figure 1. $\mathrm{SP}$ is a common procedure used to increase the near-surface strengths of metals. In the SP process, a stream of small, hard spheres is shot at a treated surface. Even in the case of ceramics, compressive residual stress is generated by localized plastic deformation or microcrack formation on the surface layer $[7,8]$. Considering the results obtained in previous

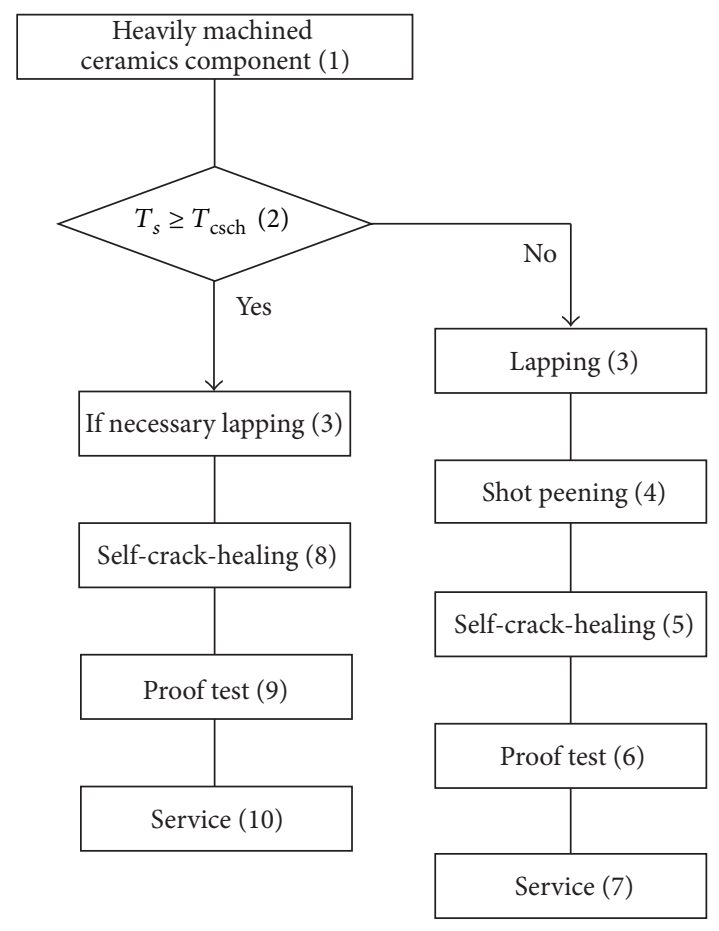

$T_{s}$ : service temperature

$T_{\text {csth }}$ : critical lower temperature for self-crack-healing

FIGURE 1: Flowchart of through-life reliability managements of ceramics components with excellent self-crack-healing ability.

studies, the SP of ceramics is a promising technique for increasing reliability in the surface region.

A high compressive residual stress will increase the fracture strength, fatigue strength, apparent fracture toughness, and contact strength of ceramics components such as bearings and turbine blades, in which higher reliability is desirable.

Self-Crack-Healing. This is related to processes nos. (5) and (8) in Figure 1. This process should be carried out under optimum conditions. In the case of process no. (5), if surface cracks are unintentionally induced or grown during the machining and SP processes, the reliability of the ceramics components will be decreased. To prevent this, the authors propose the use of a combination of SP and crack healing [6]. As a result of this combination, the surface strength and reliability of the ceramic will be improved simultaneously.

In the case of process no. (8), there is a high risk of introducing long and deep cracks by heavy machining, so a selfcrack-healing process is necessary. By this process, surface cracks introduced by machining can be healed completely, as shown in Section 4.3.

Proof Test. This is related to processes nos. (6) and (9) in Figure 1. Oxygen is necessary for crack healing, and thus embedded flaws such as pores and abnormally large grains cannot be healed. These flaws may reduce the reliability of ceramics components. It is necessary to conduct a proof test 


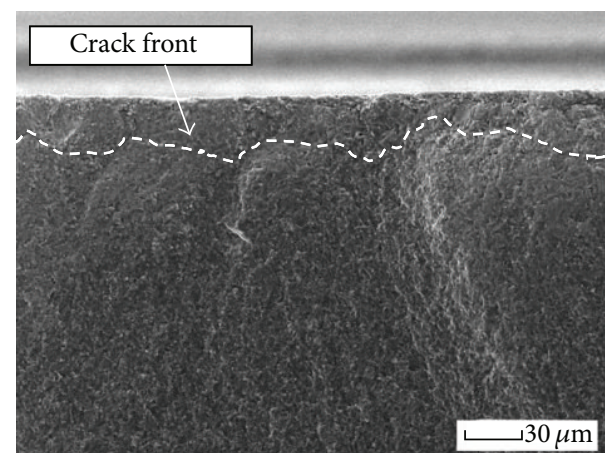

FIGURE 2: Scanning electron microscopy image of fracture surface of heavily machined specimen and crack depth induced by the machining.

to prevent the use of a low-reliability component that contains unacceptable flaws. A proof test is therefore important for achieving higher reliability. Using the proof test theory [9], the minimum fracture stress at any temperature can be evaluated easily and with high accuracy, as shown in Section 6.

Service. This is related to processes nos. (7) and (10) in Figure 1. In the case of process no. (7), $T_{s}$ is lower than $T_{\text {csch }}$ thus the materials are unable to self-heal the cracks introduced during service. Consequently, periodic heating to a higher temperature than $T_{\text {csch }}$ is a useful method of maintaining higher-level reliability of ceramics components. In contrast, in the case of process no. (10), $T_{s}$ is higher than $T_{\text {csch }}$, thus the materials are able to self-heal cracks introduced during service. Therefore, a higher level of reliability can be maintained by the self-crack-healing ability.

\section{Ceramics Materials for Service}

3.1. Nanocomposite Materials. The nanocomposite materials developed by Ando's group are described as follows [1, 2]. (a) $\mathrm{SiC}$ nanoparticles are added to the matrix, preventing grain growth in the matrix during the sintering process and improving its strength through grain refinement. For example, in the case of alumina, the bending strength can be increased from about $400 \mathrm{MPa}$ to $700-1000 \mathrm{MPa}$ by the inclusion of SiC nanoparticles [10]. (b) Composites containing 15-30 vol\% nanosized SiC particles exhibit self-crack-healing ability. (c) These SiC particles are distributed mainly in the grain boundaries. In the case of alumina, some grains are located in grains and increase the heat-proof temperature by about $300 \mathrm{~K}$. The developed ceramics materials are $\mathrm{Al}_{2} \mathrm{O}_{3} /$ $\mathrm{SiC}$, mullite/SiC, $\mathrm{Si}_{3} \mathrm{~N}_{4} / \mathrm{SiC}, \mathrm{SiC}, \mathrm{ZrO}_{2} / \mathrm{SiC}$, and $\mathrm{AlN} / \mathrm{SiC}$ $[1,2]$.

3.2. Multicomposite Materials. A multicomposite material is a composite containing $\mathrm{SiC}$ nanoparticles and $\mathrm{SiC}$ whiskers at a total volume fraction of 25-30\%. These materials have excellent self-crack-healing ability, fracture toughness, and hightemperature strength [11]. The nanosized SiC particles mainly

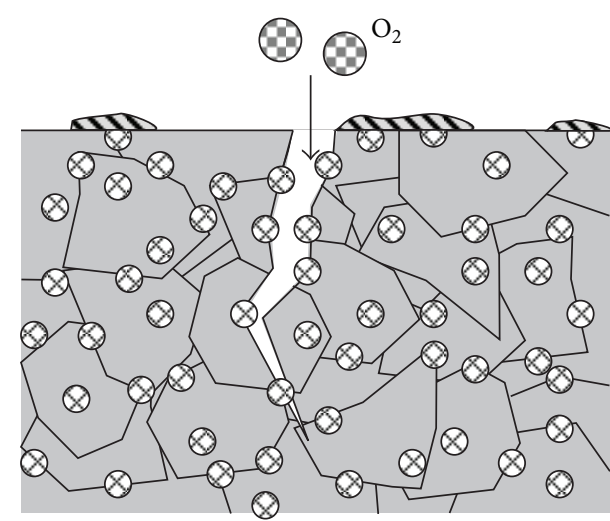

(a) Before crack healing

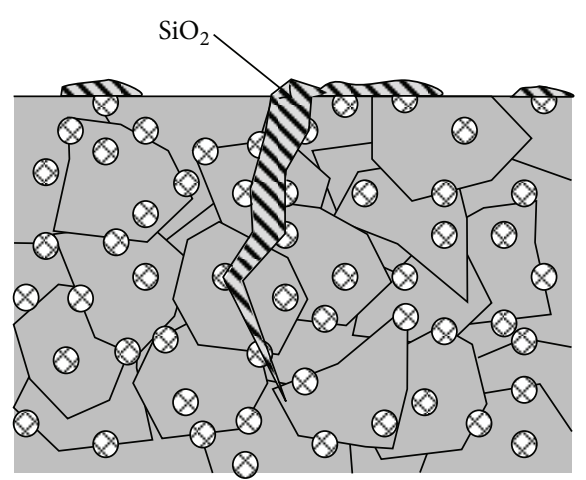

(b) After crack healing

FIGURE 3: Schematic illustration of crack-healing mechanism.

contribute to increasing the strength and self-crack-healing rate, and the $\mathrm{SiC}$ whiskers mainly contribute to increasing fracture toughness and high-temperature strength.

The proportion of $\mathrm{SiC}$ particles to $\mathrm{SiC}$ whiskers is determined by taking into consideration the self-crack-healing ability and fracture toughness requirements. The developed ceramics materials are $\mathrm{Al}_{2} \mathrm{O}_{3} / \mathrm{SiC}$ and mullite/SiC $[1,2]$.

The self-crack-healing materials described in this paper have the following three attributes. (1) The material itself detects cracks in order to begin the crack-healing process. (2) A crack that reduces the strength of the material by $50-90 \%$ can be completely healed. (3) The strength of a crack-healed area is equivalent to or higher than that of a matrix area up to about $1673 \mathrm{~K}$.

\section{Basic Self-Crack-Healing Behavior}

4.1. Mechanism of Crack Healing. The crack healing of the nanocomposite and multicomposite ceramics described in this paper is caused by the following oxidation reaction of $\mathrm{SiC}$ :

$$
\mathrm{SiC}+\frac{3}{2} \mathrm{O}_{2} \longrightarrow \mathrm{SiO}_{2}+\mathrm{CO} \quad(\Delta \mathrm{H}=-943 \mathrm{~kJ} / \mathrm{mol})
$$

From (1), it can easily be understood that a monolithic mullite or a monolithic alumina does not have a crack-healing ability, since oxidation is saturated in these materials. A 
schematic diagram of the crack-healing mechanism is shown in Figure 3. To achieve complete strength recovery by selfcrack-healing, the following three conditions are necessary. (A) The healing substance has to fill the crack completely. This condition is achieved by an increase in volume of about $80 \%$ when $\mathrm{SiC}$ is converted to $\mathrm{SiO}_{2}$. (B) The healing substance must be completely welded to the base material. This condition is satisfied by the exothermic oxidation reaction, which generates a large heat release of $943 \mathrm{~kJ}$ per mole of $\mathrm{SiC}$. The heat melts the matrix and the healing substance to form the healed mixture. (C) The strength of the crack-healed zone has to exhibit equivalent or higher strength than that of the base material up to about $1673 \mathrm{~K}$. There is a glass phase and a crystalline phase in $\mathrm{SiO}_{2}$ in (1). If the crack-healing material is crystalline $\mathrm{SiO}_{2}$, then the crack-healed sample exhibits high bending strength, even at an elevated temperature. However, if the crack-healing material is glassy $\mathrm{SiO}_{2}$, then the crackhealed sample exhibits low bending strength at an elevated temperature. A key point in crack-healing technology is how many crystalline phases are deposited in a crack-healing substance.

Three-point bending test specimens were used to evaluate the bending strength $\left(\sigma_{B}\right)$ of a crack-healed specimen. One crack was introduced into the central part of the test specimen. The crack was semielliptical in shape, with a surface length of $100 \mu \mathrm{m}$ and a depth of $45 \mu \mathrm{m}$ (hereafter called a standard crack). The authors used a shorter bending span of $16 \mathrm{~mm}$ than that typically used of $30 \mathrm{~mm}$ in order to evaluate the strengths of the crack-healed zones and to reduce the elastic energy at the fracture and prevent the specimen from breaking into small pieces.

Self-crack-healing behaviors are dependent on the material, temperature, oxygen partial pressure, and crack size (mainly depth). Figure 4 shows the effect of the atmosphere on self-crack-healing behavior [4]. The $\sigma_{B}$ of an as-received test specimen was about $650 \mathrm{MPa}$. When a standard crack was introduced into the specimen, the $\sigma_{B}$ was reduced to $180 \mathrm{MPa}$, that is, a decrease of about $73 \%$. However, when the healing of a precracked specimen was carried out in air at $1573 \mathrm{~K}$ for $1 \mathrm{~h}$, the $\sigma_{B}$ improved to about $800 \mathrm{MPa}$. The $\sigma_{B}$ of a crack-healed specimen is larger than the $\sigma_{B}$ of an as-received specimen. This is because even a smooth specimen may have minute cracks on the surface that reduce its bending strength, compared with a crack-healed specimen, in which even preexisting cracks are healed completely. However, when the precracked specimens were heated in vacuum and under $\mathrm{N}_{2}$ and argon gas atmospheres, the $\sigma_{B}$ value recovered to a maximum of $350 \mathrm{MPa}$. Under these conditions, the $\sigma_{B}$ recovery is insufficient. The slight increase in $\sigma_{B}$ achieved using this heat treatment is the result of removal of the tensile residual stress of the crack tip. Similar crack-healing and strength-recovery behaviors were reported for mullite [4], $\mathrm{Al}_{2} \mathrm{O}_{3}[12]$, and $\mathrm{Si}_{3} \mathrm{~N}_{4}[13,14]$.

Figure 5 shows specimens after the bending tests, with Figure 5(a) showing a precracked specimen [4]. The precracked specimens were fractured by cracks introduced using the Vickers indentation method. In the case of Figure 5(b), because the crack was healed completely, the fracture was initiated from outside the crack-healed zone.

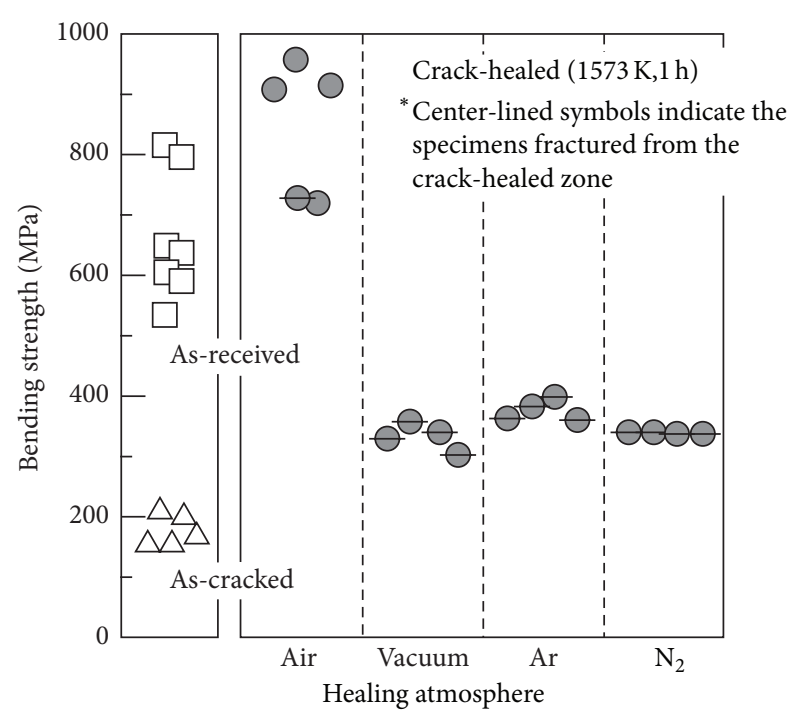

FIGURE 4: Effect of crack-healing atmosphere on crack-healing behavior of $\mathrm{Al}_{2} \mathrm{O}_{3} / \mathrm{SiC}(\mathrm{p})$ ceramics.

TABLE 1: Activation energies and proportional coefficients for crack healing.

\begin{tabular}{lcc}
\hline Material & $\begin{array}{c}\text { Activation energy } \\
Q_{H}(\mathrm{KJ} / \mathrm{mol})\end{array}$ & $\begin{array}{c}\text { Proportional coefficient } \\
Q_{0}(1 / \text { hour })\end{array}$ \\
\hline $\mathrm{Si}_{3} \mathrm{~N}_{4} / \mathrm{SiC}(\mathrm{p})$ & 277 & $4.2 \times 10^{11}$ \\
$\mathrm{Si}_{3} \mathrm{~N}_{4}$ & 150 & $5.3 \times 10^{4}$ \\
$\mathrm{Al}_{2} \mathrm{O}_{3} / \mathrm{SiC}(\mathrm{p})$ & 334 & $1.7 \times 10^{11}$ \\
Mullite/SiC $(\mathrm{p})$ & 413 & $4.7 \times 10^{13}$ \\
\hline
\end{tabular}

The influence of temperature on crack-healing behavior is shown in Figure 6 [2]. When the crack-healing times were $10 \mathrm{~h}$ and $300 \mathrm{~h}$, the temperatures corresponding to complete healing were about $1473 \mathrm{~K}$ and $1273 \mathrm{~K}$, respectively. The systematic investigations have been made on various materials to evaluate the shortest time for complete healing, $t_{H M}$, at a certain temperature $T_{H L}$. The relationship between $t_{H M}$ and $T_{H L}$ can be expressed by the Arrhenius equation as follows [15]:

$$
\frac{1}{t_{H M}}=Q_{0} \exp \left(\frac{-Q_{H}}{R T_{H L}}\right) .
$$

The activation energy $\left(Q_{H}\right)$ and proportional modulus $\left(Q_{0}\right)$ of each material were calculated, and the results are shown in Table 1 [15]. The data in Table 1 can be used to determine the relationship between $t_{H M}$ and the crack-healing temperature $T_{H L}$ for a standard crack. However, (2) is applicable for a standard crack with $t_{H M}=1-300 \mathrm{~h}$ and under ambient air. For a crack that is larger than the standard size and an oxygen partial pressure that is lower than that of air, the necessary time for complete crack healing is longer.

4.2. High-Temperature Strength of Crack-Healed Specimen. The temperature dependence on the $\sigma_{B}$ of crack-healed specimens is shown in Figure 7 [1,2]. Each test specimen was 


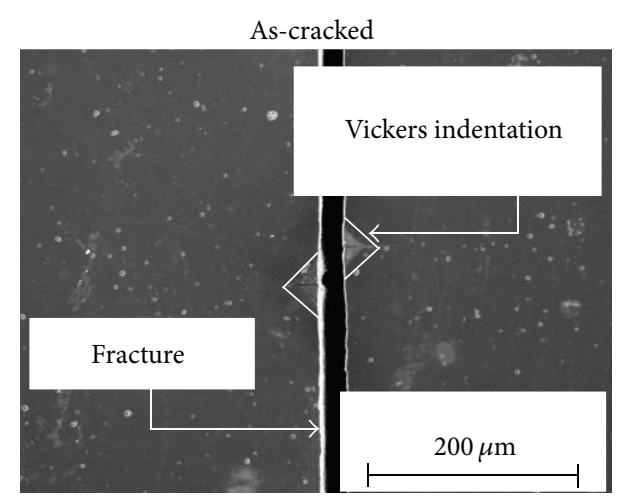

(a)

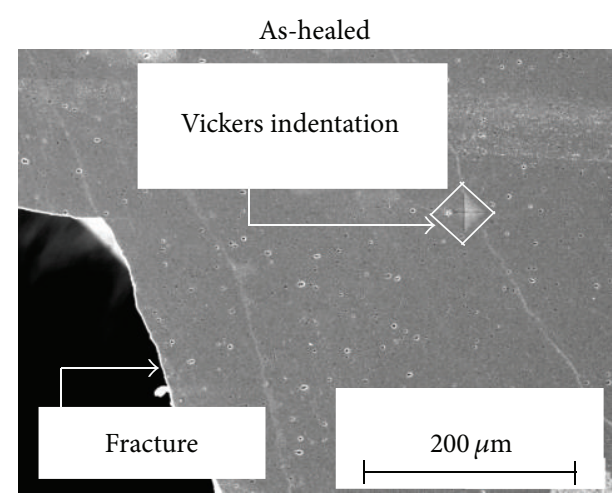

(b)

FIGURE 5: Crack path of $\mathrm{Al}_{2} \mathrm{O}_{3} / \mathrm{SiC}(\mathrm{p})$ ceramics: (a) precracked sample, crack initiated from precrack, and (b) crack-healed sample, crack initiated from outside the crack-healed zone, indicating that the crack-healed zone exhibited higher strength than that of the base material.

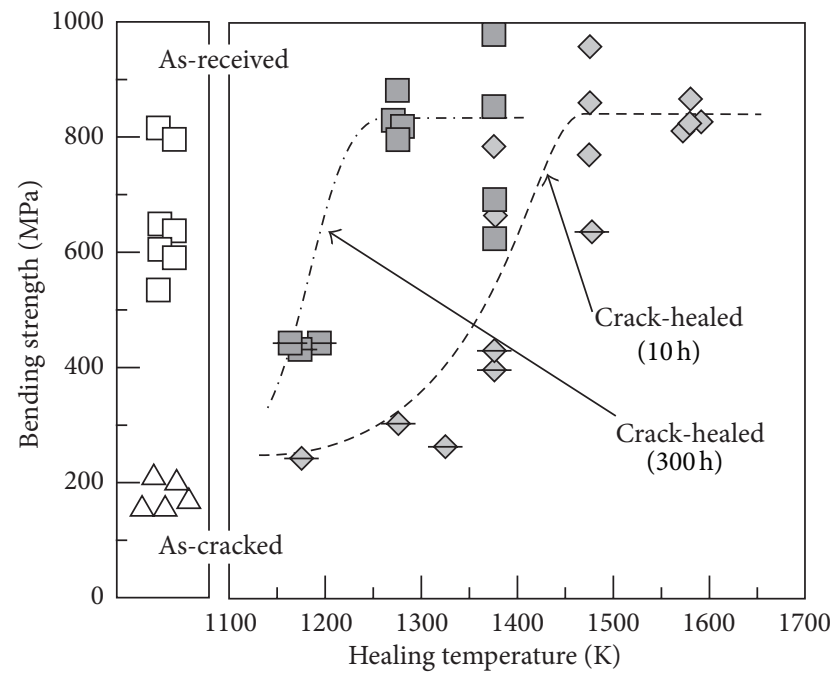

FIGURE 6: Relationship between crack-healing temperature and strength recovery for $\mathrm{Al}_{2} \mathrm{O}_{3} / \mathrm{SiC}(\mathrm{p})$ ceramics.

crack-healed under optimum conditions after a standard crack was introduced. The critical heat-proof temperature for the bending strength of $\mathrm{Al}_{2} \mathrm{O}_{3} / \mathrm{SiC}$ is about $300 \mathrm{~K}$ higher than that of monolithic $\mathrm{Al}_{2} \mathrm{O}_{3}$; this impressive increase in the critical heat-proof temperature is caused by the inclusion of SiC nanoparticles, as mentioned in Section 2. The critical heat-proof temperature at the crack-healed zone of a commercial $\mathrm{SiC}$ composite is $873 \mathrm{~K}$, which is much lower than that of the matrix [16]. As shown in the figure, a newly developed $\mathrm{SiC}$ composite exhibits an excellent critical heat-proof temperature of about $1673 \mathrm{~K}$ in the crack-healed zone, and we examined its use [17]. The critical heat-proof temperature of a silicon nitride composite, with $\mathrm{Al}_{2} \mathrm{O}_{3}$ added to it, was about $1273 \mathrm{~K}$. The critical heat-proof temperature of the new silicon nitride, which has an improved composition system, is about $1673 \mathrm{~K}$, which is higher than the critical heatproof temperature of the silicon nitride with added $\mathrm{Al}_{2} \mathrm{O}_{3}$. The large improvement in the critical heat-proof temperature was attained by the crystallization of a grain boundary phase

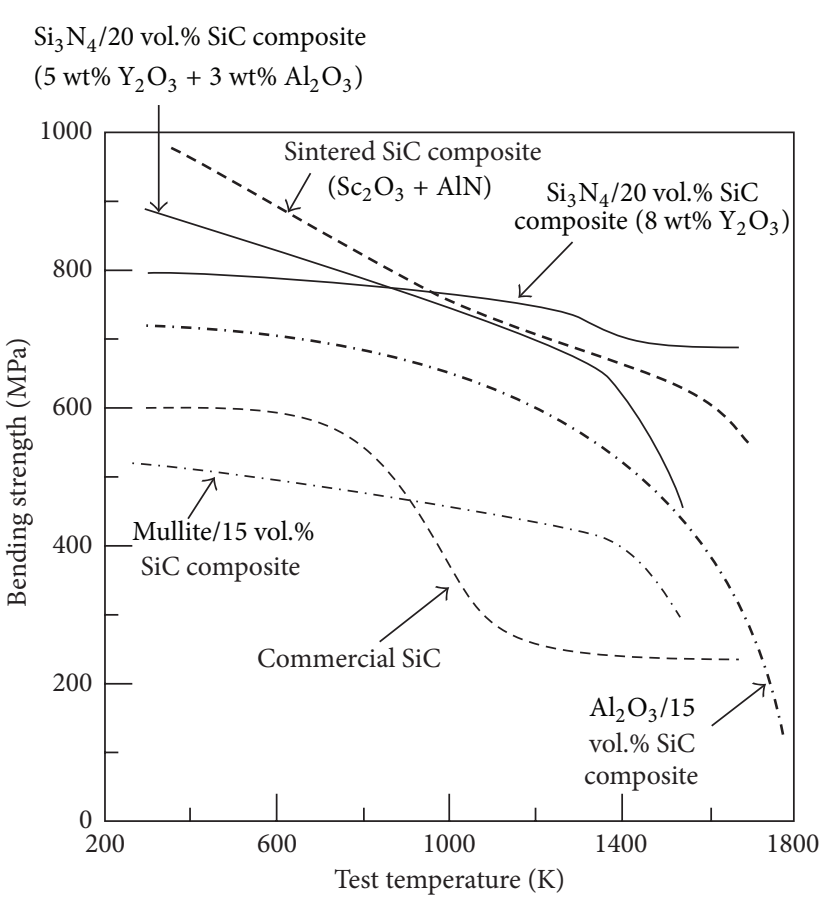

FIGURE 7: Effect of test temperature on bending strengths of crackhealed ceramics.

and a crack-healing substance. It should also be noted that the various types of composites, except the commercial $\mathrm{SiC}$ composite, fractured from a site other than the crack-healed zone within the temperature range below the critical heatproof temperature. This implied that the crack-healing zone had sufficient bending strength even at high temperatures.

4.3. Crack-Healing Behavior of Heavily Machined Component. The crack-healing behaviors of heavily machined specimens have been investigated by several researchers $[3,18,19]$. The experimental results showing the effects of crack healing in increasing the reliability of machined components have been explained [3]. Sintered plates of $\mathrm{Al}_{2} \mathrm{O}_{3} / 20 \mathrm{vol} \% \mathrm{SiC}$ 
whiskers were cut into $3 \mathrm{~mm} \times 4 \mathrm{~mm} \times 22 \mathrm{~mm}$ rectangular bar specimens. A semicircular groove was made at the center of the smooth specimens using a diamond-coated ball drill, as shown in Figure 8 . The cut depth from one pass $\left(d_{c}\right)$ during machining of the semicircular groove was $d_{c}=5-15 \mu \mathrm{m}$. The total cut depth was $0.5 \mathrm{~mm}$. The fracture tests were conducted at room temperature. The local fracture stresses $\left(\sigma_{L F}\right)$ related to the stress concentration factor of the semicircular groove ( $\alpha=1.2)$ were evaluated. Figure 8 shows the strength of the machined specimens with a semicircular groove as a function of the cut depth by one pass $\left(d_{c}\right)$. The open triangle symbols show the local fracture stresses $\left(\sigma_{L F}\right)$ of the asmachined specimen. The $\sigma_{L F}$ of the as-machined specimens decreased with increasing $d_{c}$. This behavior was caused by the fact that the crack depth caused by machining increased with increasing $d_{c}$. Figure 2 shows scanning electron microscope images of the fracture surface of the as-machined specimen. The dashed lines in Figure 2 indicate the crack front. As shown in this figure, these surface cracks acted as fracture initiators. Thus, the $\sigma_{L F}$ values of the as-machined specimens decreased compared with those of the healed smooth specimens. The open square symbols in Figure 8 show the $\sigma_{L F}$ of the machined specimen healed at $1673 \mathrm{~K}$ for $10 \mathrm{~h}$ in air. The $\sigma_{L F}$ of these specimens increased significantly as a result of crack healing. The $\sigma_{L F}$ values of the machined specimens were almost equal to the fracture stress of the healed smooth specimens (solid circles). Thus, the surface cracks introduced by the heavy machining process were healed. It was therefore concluded that crack healing could be an effective method for improving the structural integrity of machined ceramics with self-crack-healing abilities and reducing machining costs.

\section{Crack-Healing Behavior during Service}

Ceramics components are often exposed to continuous constant or cyclic loading at elevated temperatures under low oxygen partial pressures. If a crack is initiated during service, the component's reliability will be considerably reduced. If the crack can be healed under service conditions and the components recover their strength completely, the reliability and lifetime of ceramics components can be increased. Crackhealing behavior under constant or cyclic stress has been systematically studied for $\mathrm{Si}_{3} \mathrm{~N}_{4} / \mathrm{SiC}[5,20]$, mullite/SiC [21, 22], $\mathrm{Al}_{2} \mathrm{O}_{3} / \mathrm{SiC}$ [23], and $\mathrm{SiC}$ [17]. Standard precracks were healed, and the samples completely recovered their strength at the healing temperature, even under constant or cyclic stress.

To take advantage of a material's crack-healing ability during service, it is essential to determine its threshold stress for crack healing, under which a crack can be completely healed. In this section, the critical stress conditions for crack healing in $\mathrm{Si}_{3} \mathrm{~N}_{4} / \mathrm{SiC}$ and other ceramics are shown.

5.1. Crack-Healing Behavior of $\mathrm{Si}_{3} \mathrm{~N}_{4} / \mathrm{SiC}$ under Stress and Low Oxygen Pressure. The material studied was hot-pressed $\mathrm{Si}_{3} \mathrm{~N}_{4}$, which contained $20 \mathrm{wt} \% \mathrm{SiC}$ particles and $8 \mathrm{wt} \% \mathrm{Y}_{2} \mathrm{O}_{3}$ as a sintering additive [24]. A semicircular surface crack of surface length $100 \mu \mathrm{m}$ (standard crack) was introduced at the

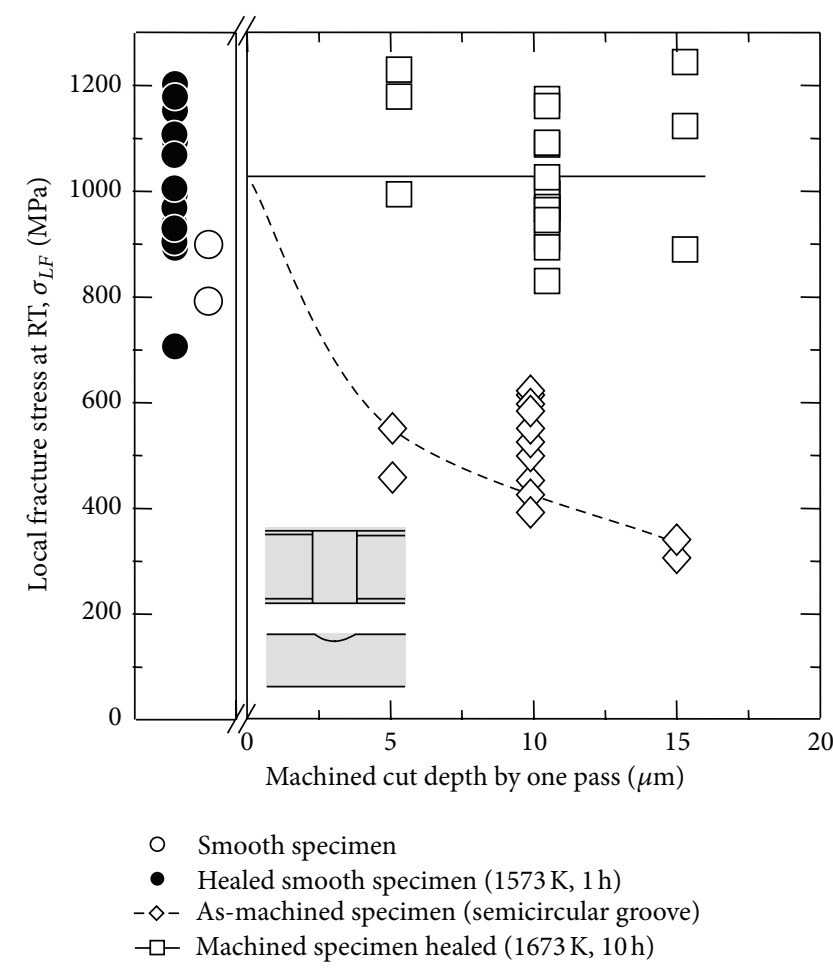

FIGURE 8: Effect of crack healing on local fracture stress at room temperature as a function of depth of cut by one pass.

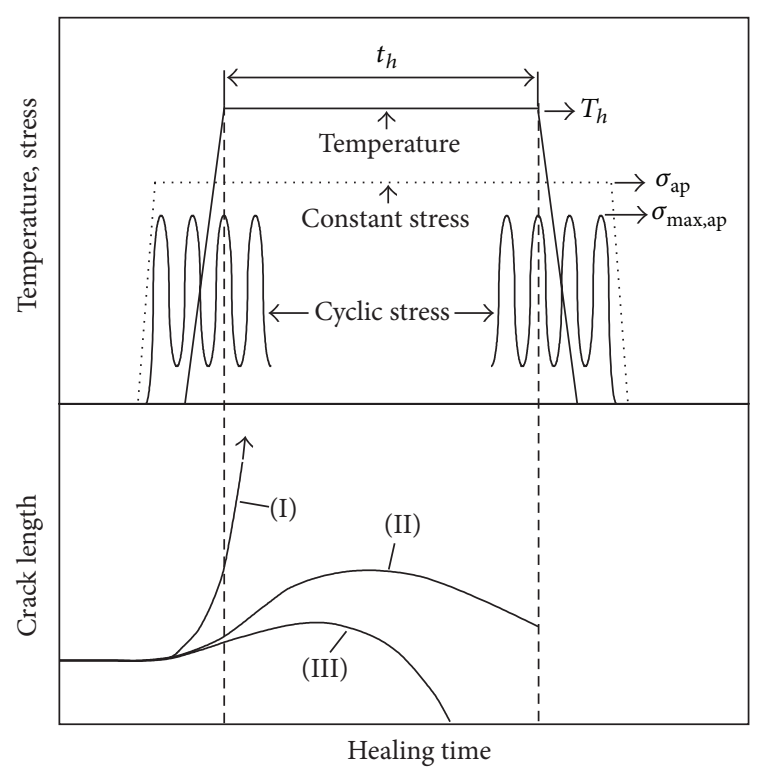

FIGURE 9: Schematic illustration of crack healing under stress and crack growth or healing behaviors.

center of the tensile surface of the bending test specimens. After introducing the precracks, crack-healing tests under cyclic or constant stress were carried out. Figure 9 shows the crack-healing process [24].

Crack healing was carried out under cyclic $\left(\sigma_{\max , a p}\right)$ or constant $\left(\sigma_{\mathrm{ap}}\right)$ bending stresses at the healing temperature $\left(T_{h}\right)$ for a prescribed healing time $\left(t_{h}\right)$. After the crack-heal- 


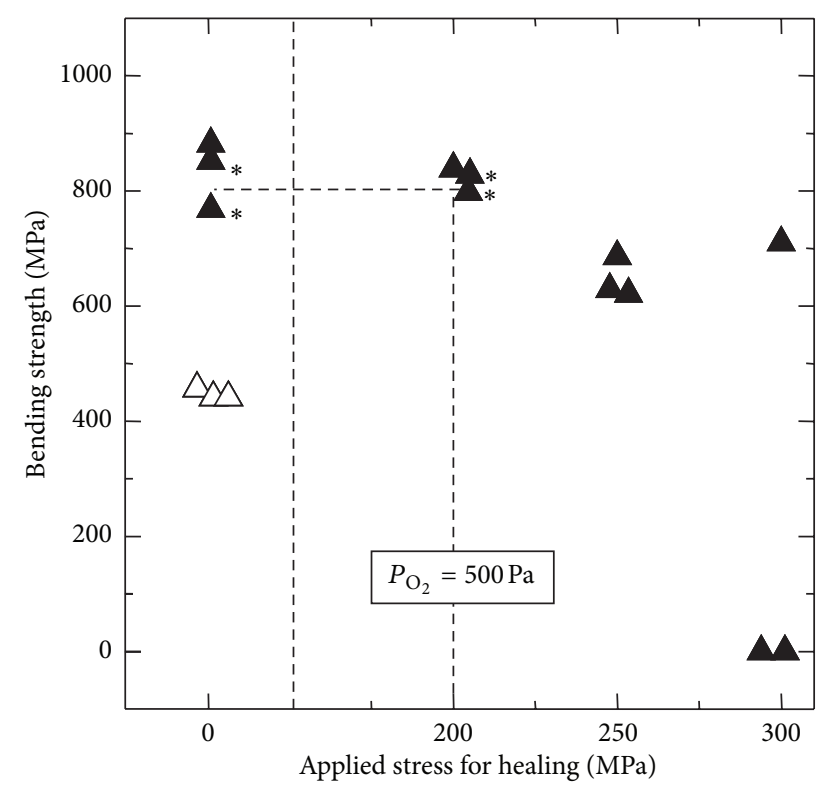

$\triangle$ As-cracked specimen $(2 \mathrm{C}=100 \mu \mathrm{m})$
${ }^{*}$ Crack-healed under constant stress at $1200^{\circ} \mathrm{C}$ for $5 \mathrm{~h}$ in $P_{\mathrm{O}_{2}}$

FIGURE 10: Room-temperature bending strength of crack healed specimens as a function of applied stress during crack healing under $P_{\mathrm{O}_{2}}=500 \mathrm{~Pa}$ at $1473 \mathrm{~K}\left[\mathrm{Si}_{3} \mathrm{~N}_{4} / \mathrm{SiC}(\mathrm{p})\right]$.

ing process, the bending strengths of the specimens were measured at room temperature or at the healing temperature in air.

Figure 10 shows the results of the bending tests on specimens crack-healed at $1473 \mathrm{~K}$ for $5 \mathrm{~h}$ under constant stress with $P_{\mathrm{O}_{2}}=500 \mathrm{~Pa}$ [24]. The solid triangles represent the bending strengths of the crack-healed specimens. Open triangles indicate the bending strengths of the precracked specimens. The asterisks indicate specimens that fractured outside the crack-healed zone, suggesting that the precracks were healed completely. The threshold stress for crack healing was defined as the maximum stress below which the crackhealed specimens recovered their bending strength, and below which most specimens fractured outside the crackhealed zone.

From Figure 10, the threshold stress for crack healing in air was determined to be $200 \mathrm{MPa}$. A similar crack-healing test under cyclic stress was carried out using $\mathrm{Si}_{3} \mathrm{~N}_{4} / \mathrm{SiC}$, $\mathrm{Al}_{2} \mathrm{O}_{3} / \mathrm{SiC}(\mathrm{p}), \mathrm{Al}_{2} \mathrm{O}_{3} / \mathrm{SiC}(\mathrm{w})$, and mullite/SiC, and the threshold stress was found to be $100-300 \mathrm{MPa}$. All of the materials exhibited higher threshold stress under cyclic testing than under constant stress.

The above test results indicate that the $\mathrm{Si}_{3} \mathrm{~N}_{4} / \mathrm{SiC}$ composite is able to recover its strength completely, even under service conditions, that is, with an applied stress below $\sigma_{\text {ap }}=$ $200 \mathrm{MPa}$ and an oxygen partial pressure above $500 \mathrm{~Pa}$.

As to the effect of $P_{\mathrm{O}_{2}}$ on the threshold stress, if $P_{\mathrm{O}_{2}}$ is higher than $500 \mathrm{~Pa}$, the threshold stress is independent of $P_{\mathrm{O}_{2}}$. However, below $P_{\mathrm{O}_{2}}=50 \mathrm{~Pa}$, the threshold stress has a slightly lower value. The specimens crack-healed under a constant stress of $200 \mathrm{MPa}$ showed comparable bending strengths to those of specimens crack-healed under no stress.

The crack-healing behavior under stress is shown in Figure 9 [5]. The changes in the crack length during crack healing are divided into three cases. In case (I), slow crack growth from the tip of the precrack occurs, and the cracks lead to specimen failure because the crack-growth rate is higher than the crack-healing rate. In case (II), slow crack growth from the tip of the precrack also occurs. The crackhealing process starts at high temperature, causing a decrease in the crack-growth rate, as a result of crack healing, and finally the cracks are healed. In case (III), slow crack growth from the precrack does not occur, and the precracks are easily healed completely.

The threshold stresses (constant or cyclic) for crack healing as a function of the bending strengths of the precracked specimens were tested systematically using the above mentioned materials [11]. All the data have proportional relationships, in spite of differences in crack-healing conditions. For precracked specimens under constant stress, the threshold stress is $64 \%$ of the bending strength, and for precracked specimens under cyclic stress, the threshold stress is $76 \%$ of the bending strength.

5.2. Strength of Crack-Healed Sample at Healed Temperature and Fatigue Limit. The test material was $\mathrm{Si}_{3} \mathrm{~N}_{4} / \mathrm{SiC}(\mathrm{p})$, and a standard crack was introduced in the sample. The crack was healed at a temperature between $1173 \mathrm{~K}$ and $1473 \mathrm{~K}$ under cyclic stress [5]. The cyclic stress conditions during crack healing were as follows: maximum stress $\sigma_{\max }=210 \mathrm{MPa}$, stress ratio $R=0.2$, and frequency $f=5 \mathrm{~Hz}$. The bending strength $\left(\sigma_{B}\right)$ and the cyclic fatigue limit $\left(\sigma_{f 0}\right)$ at the healing temperature are shown in Figure 11 by solid circles and open squares, respectively. Furthermore, the bending strength of a run out specimen in a fatigue test at the healing temperature is shown in Figure 11 by solid triangles. An asterisk indicates that fracture occurred from outside the crack-healed zone. Similar tests have been made above mentioned $\mathrm{Al}_{2} \mathrm{O}_{3} / \mathrm{SiC}$, mullite/SiC, $\mathrm{Si}_{3} \mathrm{~N}_{4} / \mathrm{SiC}$, and $\mathrm{SiC}$. From Figure 11 and these tests results, the following three conclusions can be obtained. (1) The strength of the crack-healed zone was the same as or higher than that of the base material, even at the crackhealed temperature, because many samples fractured from base material. (2) The fatigue limit is almost equal to the bending strength. This indicates that cracks initiated during the fatigue test, are healed during the fatigue test and the material recovers its strength completely. (3) The properties described in (1) and (2) are very useful for the through-life reliability of ceramics components.

\section{Proof Test Theory}

As mentioned above, oxygen is necessary for crack healing, and thus embedded flaws such as pores and abnormally large grains cannot be healed.

So, for higher reliability, a proof test is necessary. Generally, a proof test is conducted at room temperature, for economic reasons. If the proof-tested components are used at 


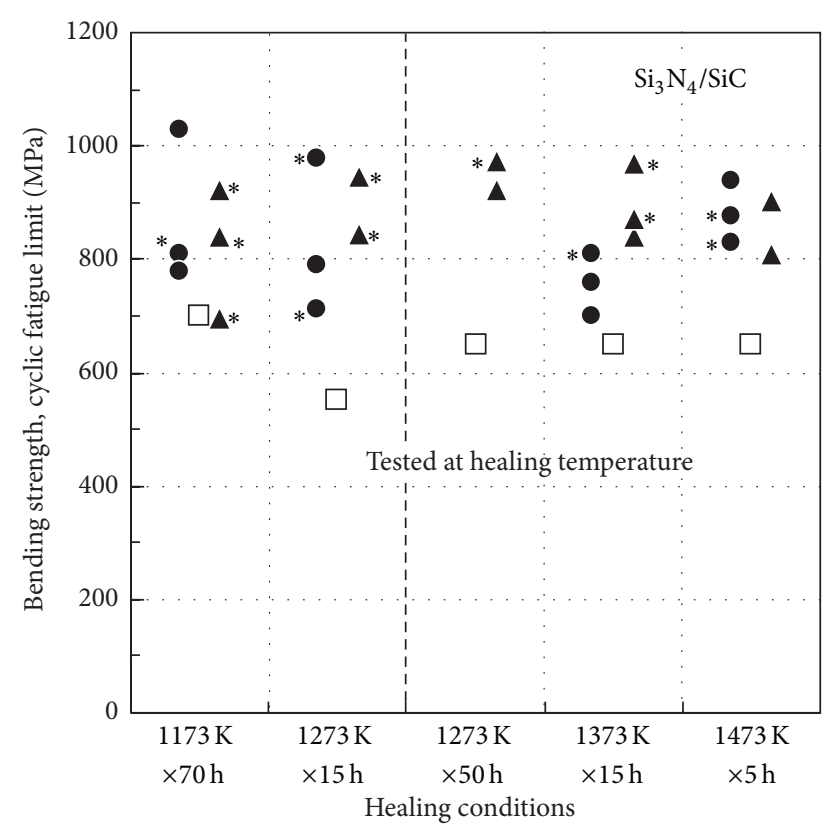

- $\sigma_{B}$ of crack-healed specimen

$\square$ Cyclic fatigue limit of crack-healed specimen (cyclic fatigue test conditions: $R=0.2,5 \mathrm{~Hz}$ )

$\Delta \sigma_{B}$ of fatigue-tested specimen

FIGURE 11: Results of bending tests and fatigue tests on $\mathrm{Si}_{3} \mathrm{~N}_{4} / \mathrm{SiC}(\mathrm{p})$ at healing temperatures between $1173 \mathrm{~K}$ and $1473 \mathrm{~K}$. Cyclic stress during crack healing: maximum stress $\sigma_{\max }=210 \mathrm{MPa}$, stress ratio $R$ $=0.2$, frequency $f=5 \mathrm{~Hz}$. Asterisk indicates that fracture occurred from outside the crack-healed zone, indicating that the crack-healed zone exhibited higher strength than that of the base material.

room temperature, the guaranteed (minimum) fracture stress $\left(\sigma_{G}\right)$ of the proof-tested component is equal to the proof test stress $\left(\sigma_{p}\right)$. However, in most cases, proof-tested components are used at elevated temperatures. Thus, a new theory is necessary that is able to evaluate $\sigma_{G}$ at elevated temperatures. The proposed theory is shown as (3) [9]

$$
\begin{aligned}
& \sigma_{G} \\
& =\frac{2 \sigma_{0}^{T}}{\pi} \arccos \left\{\left(\frac{K_{I C}^{T}}{K_{I C}^{R}}\right)^{2}\left(\frac{\sigma_{0}^{R}}{\sigma_{0}^{T}}\right)^{2}\left\{\sec \left(\frac{\pi \sigma_{p}^{R}}{2 \sigma_{0}^{R}}\right)-1\right\}+1\right\}^{-1},
\end{aligned}
$$

where $\sigma_{0}$ and $\sigma_{p}^{R}$ are the strength of the plain specimen (intrinsic bending strength) and the proof test stress at room temperature, respectively, and $K_{I C}$ is the plane strain fracture toughness. In (3), the superscripts $R$ and $T$ to $\sigma_{G}, \sigma_{0}$, and $K_{I C}$ indicate the value at room temperature and the value at elevated temperature $T$, respectively.

The proof test theory was applied to $\mathrm{Si}_{3} \mathrm{~N}_{4}$ [9], $\mathrm{Al}_{2} \mathrm{O}_{3}$ / $\mathrm{SiC}(\mathrm{p})$ [25], and a coiled spring made of $\mathrm{Si}_{3} \mathrm{~N}_{4}$ [26]. The test results are shown in Figure 12; the measured minimum fracture stresses $\left(\sigma_{F \text { min }}\right)$ are plotted as a function of the evaluated $\sigma_{G}$. N in the figure denotes the number of samples used to obtain $\sigma_{F \min }$, and $N$ is $9-15$. The standard $N$ is 15 .
The four solid diamonds indicate the data on the ceramic coiled spring made of silicon nitride. All the $\sigma_{F \text { min }}$ values showed good agreement with $\sigma_{G}$, regardless of the test temperature. From this figure, it can be concluded that (3) can be applied to $\mathrm{Al}_{2} \mathrm{O}_{3} / \mathrm{SiC}, \mathrm{Si}_{3} \mathrm{~N}_{4}$, and even to a coiled spring.

\section{Shot Peening}

SP was applied to $\mathrm{Si}_{3} \mathrm{~N}_{4} / \mathrm{SiC}$ with excellent self-crack-healing ability. A maximum compressive residual stress of $880 \mathrm{MPa}$ was observed at the surface. The compressive residual stress decreased in the depth direction. The compressive residual stress was induced up to a depth of approximately $40 \mu \mathrm{m}$. Figure 13 shows the residual stress at the surface as a function of the heat-treatment temperature [6]. The compressive residual stress decreased with increasing heat-treatment temperature. However, the specimen heat treated at $800-1100^{\circ} \mathrm{C}$ showed compressive residual stresses of $300-400 \mathrm{MPa}$. In $\mathrm{Si}_{3} \mathrm{~N}_{4} / \mathrm{SiC}$, crack healing occurred above $800^{\circ} \mathrm{C}$.

The effect of SP on the apparent fracture toughness was evaluated using the indentation fracture (IF) method. The average value of the fracture toughness $\left(K_{I C}\right)$ for non-SP specimens, measured using the standard $K_{I C}$ test method, was $4.9 \mathrm{MP} \mathrm{am}^{1 / 2}$. Thus, the values of the apparent fracture toughness $\left(K_{C}\right)$ of the non-SP specimens, measured using the IF method $\left(K_{C}=4.1 \mathrm{MP} \mathrm{am}^{1 / 2}\right)$, were close to the $K_{I C}$ of the material. The $K_{C}$ of the SP specimens was about $10 \mathrm{MP} \mathrm{am}^{1 / 2}$, as shown in Figure 14. The $K_{C}$ increased 2.3-fold compared with that of the non-SP specimen. Figure 14 shows the relationship between the heat-treatment temperature and $K_{C}$ [6]. After heat treatment, the $K_{C}$ for the SP specimens decreased. However, if the heat-treatment temperature was $800-1100^{\circ} \mathrm{C}$, at which crack healing is possible, the $K_{C}$ after heat treatment was more than twice as large.

The effect of SP on the contact strength was also investigated systematically [6]. The critical load, $P_{c}$, for crack initiation of non-SP specimens was $0.5 \mathrm{kN}$, whereas the $P_{c}$ for SP specimens was more than $4.5 \mathrm{kN}$, which was the maximum load of the testing system. Thus, the $P_{c}$ increased more than ninefold as a result of SP. The $P_{c}$ for the SP + heat-treated specimens decreased with increasing heat-treatment temperature. The tendency of $P_{c}$ to decrease with increasing heattreatment temperature was similar to that of $K_{C}$. This is because both $K_{C}$ and $P_{c}$ are closely related to the compressive residual stress. The author noted that the $P_{c}$ values of the SP + heat-treated specimens were four times higher than those of the non-SP specimens if the heat-treatment temperature was $1100^{\circ} \mathrm{C}$, at which crack healing was possible. From the above test results, it can be concluded that the combination of SP and self-crack-healing is a useful technology for improving the surface strength and reliability of ceramics components.

For measurement of bending strength, non-SP and SP specimens of $\mathrm{Si}_{3} \mathrm{~N}_{4} / \mathrm{SiC}$ were prepared [6]. A Vickers indentation was made on the center of the polished face of the nonSP and SP specimens at loads of 19.6 to $98.0 \mathrm{~N}$ to simulate the surface cracks introduced by shot peening or other contact events. These specimens are called "non-SP + cracked" 

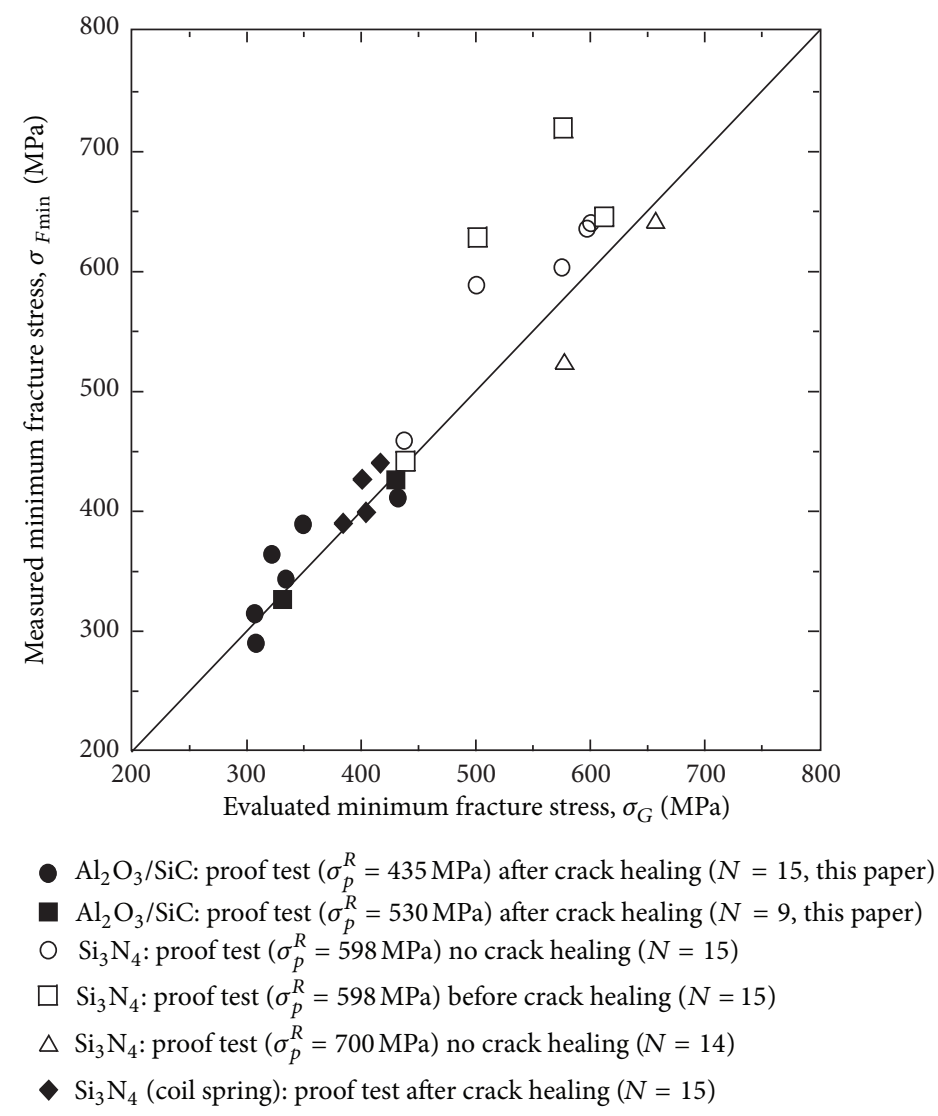

FIGURE 12: Relationship between measured minimum fracture stress of proof-tested sample and minimum fracture stress evaluated using (2).

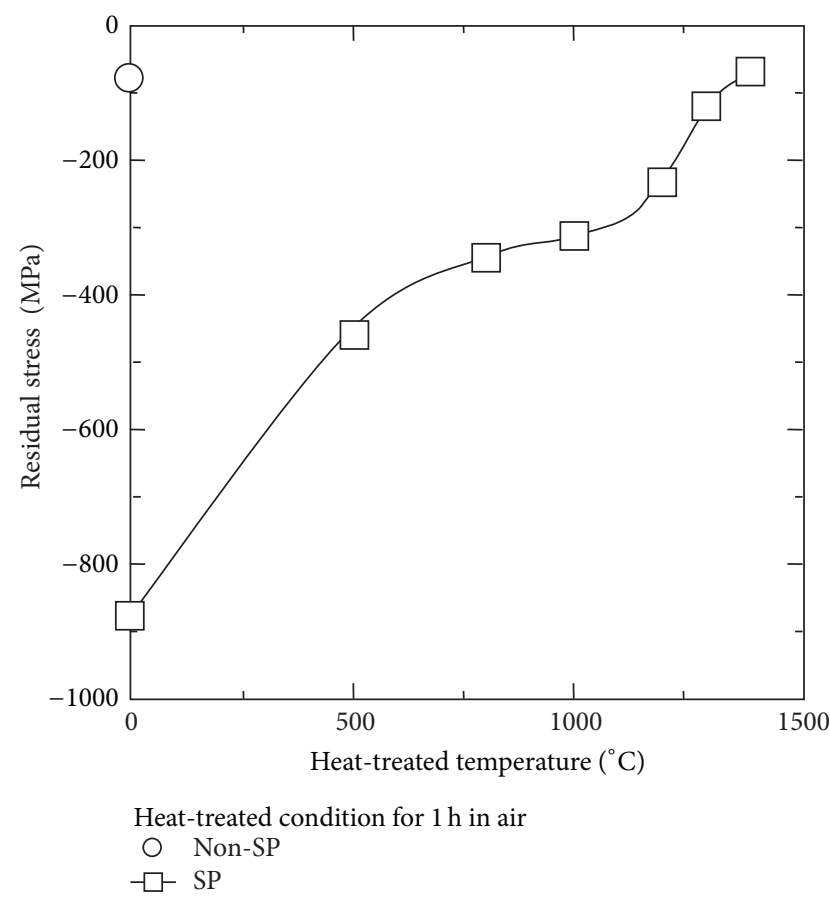

FIgURE 13: Compressive residual stress at surface as a function of heat-treatment temperature. Compressive residual stress was induced by shot peening at room temperature. and "SP + cracked" specimens, respectively. The specimens were subsequently tested in three-point bending at a crosshead speed of $0.5 \mathrm{~mm} / \mathrm{min}$, using a fixture with a span of $16 \mathrm{~mm}$. Figure 15 shows the bending strength as a function of Vickers indentation load. The bending strength of non-SP + cracked specimens (solid triangles) decreased steeply with increasing Vickers indentation loads, although the decrease rates of the bending strength of SP + cracked specimens (solid inverse triangles) were smaller than that of non-SP + cracked specimens. The main reason for this is that the compressive residual stress restrained initiation and propagation of crack in SP + cracked specimens. These results indicate that the shot peening increased the strength at the subsurface of the test material.

\section{Conclusion}

Structural ceramics are generally brittle, which seriously affects the reliability of ceramics components. Five methods are typically used to overcome this weakness: (a) fiber reinforcement or microstructural control to toughen the ceramic, (b) high-level nondestructive inspection and repair of dangerous flaws, (c) proof testing to select components with high reliability, (d) using materials with excellent self-crack-healing ability, and (e) introducing compressive residual stress on 


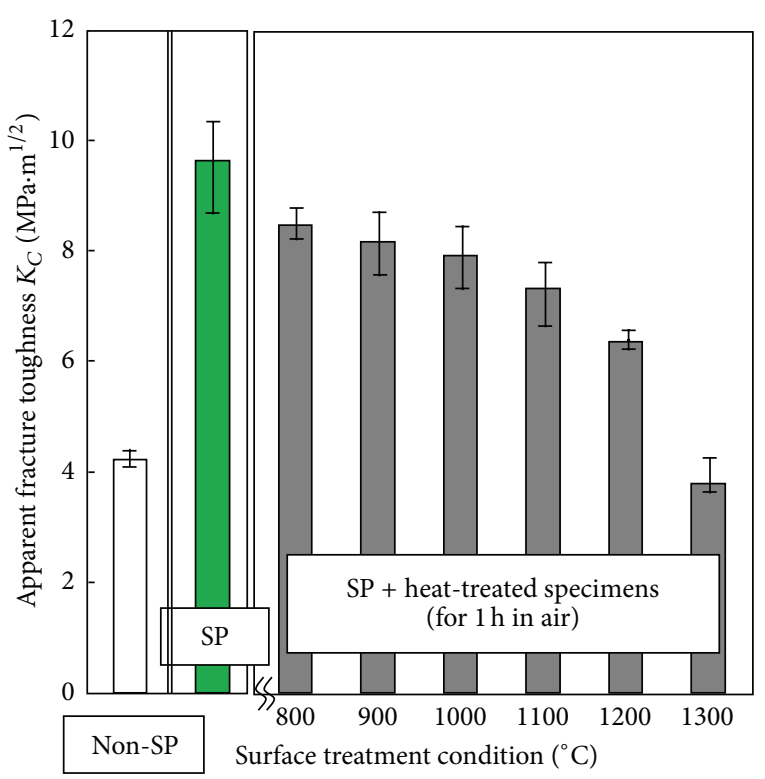

FIgURE 14: Apparent fracture toughness at room temperature as a function of heat-treatment temperature. Apparent fracture toughness was considerably increased by shot peening.

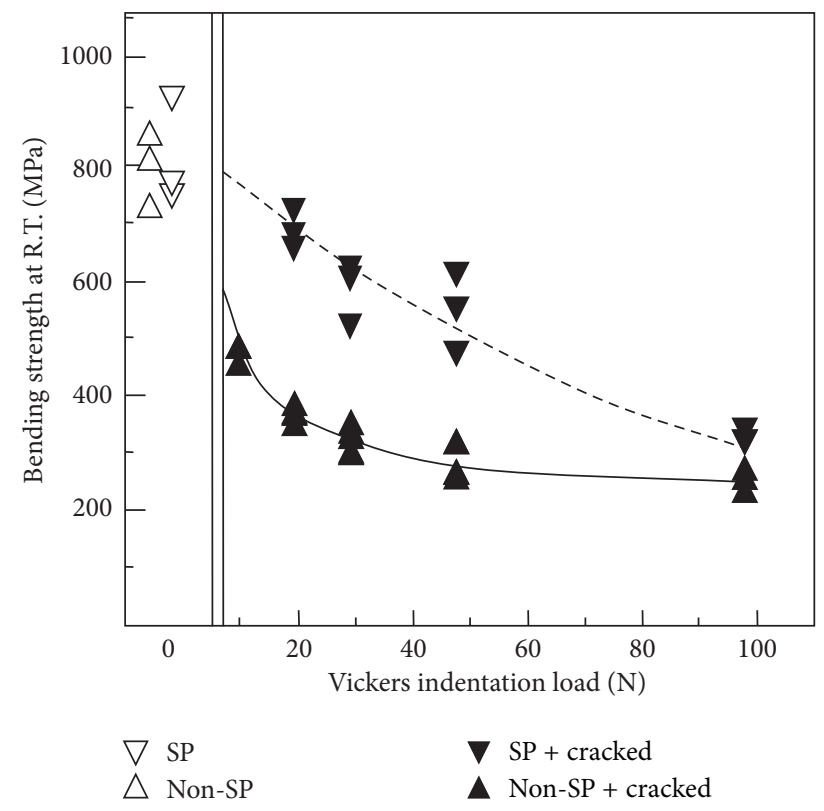

FIgURE 15: Relationship between indentation load and bending strength.

the surface layer. It is impossible to increase the through-life reliability of ceramics components using only one of the above technologies. Thus, it is important to combine these technologies. There are very few studies on how best to combine these technologies to increase the through-life reliability of ceramics components. In this paper, special attention was paid to methods (a), (c), (d), and (e), and a new methodology was proposed, as shown in Figure 1. Moreover, each process was explained in detail.

\section{References}

[1] W. Nakao, K. Takahashi, and K. Ando, "Self-healing of surface cracks in structural ceramics," in Self-Healing Materials, S. K. Ghosh, Ed., chapter 6, pp. 183-217, Wiley-VCH, Weinheim, Germany, 2009.

[2] K. Ando, K. Takahashi, and W. Nakao, "Self-crack-healing behavior of structural ceramics," in Handbook of Nanoceramics and Their Based Nanodevices, T. Y. Tseng and H. S. Nalwa, Eds., vol. 1, chapter 3, pp. 1-26, American Scientific Publishers, Valencia, Calif, USA, 2009.

[3] T. Osada, W. Nakao, K. Takahashi, K. Ando, and S. Saito, "Strength recovery behavior of machined alumina/SiC whisker composite by crack-healing," Journal of the Ceramic Society of Japan, vol. 115, no. 1340, pp. 278-284, 2007.

[4] M. C. Chu, S. Sato, Y. Kobayashi, and K. Ando, "Damage healing and strengthening behaviour in intelligent mullite/SiC ceramics," Fatigue \& Fracture of Engineering Materials \& Structures, vol. 18, no. 9, pp. 1019-1029, 1995.

[5] K. Takahashi, K. Ando, H. Murase, S. Nakayama, and S. Saito, "Threshold stress for crack-healing of $\mathrm{Si}_{3} \mathrm{~N}_{4} / \mathrm{SiC}$ and resultant cyclic fatigue strength at the healing temperature," Journal of the American Ceramic Society, vol. 88, no. 3, pp. 645-651, 2005.

[6] K. Takahashi, Y. Nishio, Y. Kimura, and K. Ando, "Improvement of strength and reliability of ceramics by shot peening and crack healing," Journal of the European Ceramic Society, vol. 30, no. 15, pp. 3047-3052, 2010.

[7] T. Frey and W. Pfeiffer, "Shot peening of ceramics: damage or benefit?” in Shot Peening, L. Wgner, Ed., pp. 185-190, WileyVCH, Weinheim, Germany, 2003.

[8] W. Pfeiffer and T. Frey, "Strengthening of ceramics by shot peening," Journal of the European Ceramic Society, vol. 26, no. 13, pp. 2639-2645, 2006.

[9] K. Ando, Y. Shirai, M. Nakatani, Y. Kobayashi, and S. Sato, "(Crack-healing + proof test): a new methodology to guarantee the structural integrity of a ceramics component," Journal of the European Ceramic Society, vol. 22, no. 1, pp. 121-128, 2002.

[10] K. Ando, B. S. Kim, M. C. Chu, S. Saito, and K. Takahashi, "Crack-healing and mechanical behaviour of $\mathrm{Al}_{2} \mathrm{O}_{3} / \mathrm{SiC}$ composites at elevated temperature," Fatigue \& Fracture of Engineering Materials \& Structures, vol. 27, no. 7, pp. 533-541, 2004.

[11] W. Nakao, K. Takahashi, and K. Ando, “Threshold stress during crack-healing treatment of structural ceramics having the crack-healing ability," Materials Letters, vol. 61, no. 13, pp. 27112713, 2007.

[12] I. A. Chou, H. M. Chan, and M. P. Harmer, "Effect of annealing environment on the crack healing and mechanical behavior of silicon carbide-reinforced alumina nanocomposites," Journal of the American Ceramic Society, vol. 81, no. 5, pp. 1203-1208, 1998.

[13] K. Ando, T. Ikeda, S. Sato, F. Yao, and Y. Kobayasi, "A preliminary study on crack healing behaviour of $\mathrm{Si}_{3} \mathrm{~N}_{4} / \mathrm{SiC}$ composite ceramics," Fatigue \& Fracture of Engineering Materials \& Structures, vol. 21, no. 1, pp. 119-122, 1998.

[14] Y. S. Jung, W. Nakao, K. Takahashi, K. Ando, and S. Saito, "Crack-healing behavior of $\mathrm{Si}_{3} \mathrm{~N}_{4} / \mathrm{SiC}$ composite under low oxygen partial pressure," Journal of the Society of Materials Science, Japan, vol. 57, no. 11, pp. 1132-1137, 2008.

[15] K. Ando, K. Furusawa, K. Takahashi, M. C. Chu, and S. Sato, "Crack-healing behavior of structural ceramics under constant and cyclic stress at elevated temperature," Journal of the Ceramic Society of Japan, vol. 110, no. 1284, pp. 741-747, 2002. 
[16] S. K. Lee, W. Ishida, S. Y. Lee, K. W. Nam, and K. Ando, "Crackhealing behavior and resultant strength properties of silicon carbide ceramic," Journal of the European Ceramic Society, vol. 25, no. 5, pp. 569-576, 2005.

[17] S. K. Lee, K. Ando, and Y. W. Kim, "Effect of heat treatments on the crack-healing and static fatigue behavior of silicon carbide sintered with $\mathrm{Sc}_{2} \mathrm{O}_{3}$ and AlN," Journal of the American Ceramic Society, vol. 88, no. 12, pp. 3478-3482, 2005.

[18] S. K. Lee, M. Ono, W. Nakao, K. Takahashi, and K. Ando, "Crack-healing behaviour of mullite $/ \mathrm{SiC} / \mathrm{Y}_{2} \mathrm{O}_{3}$ composites and its application to the structural integrity of machined components," Journal of the European Ceramic Society, vol. 25, no. 15, pp. 3495-3502, 2005.

[19] Y. S. Jung, Y. Guo, W. Nakao, K. Takahashi, K. Ando, and S. Saito, "Crack-healing behaviour and resultant high-temperature fatigue strength of machined $\mathrm{Si}_{3} \mathrm{~N}_{4} / \mathrm{SiC}$ composite ceramic," Fatigue \& Fracture of Engineering Materials \& Structures, vol. 31, no. 1, pp. 2-11, 2008.

[20] K. Ando, K. Takahashi, S. Nakayama, and S. Saito, "Crackhealing behavior of $\mathrm{Si}_{3} \mathrm{~N}_{4} / \mathrm{SiC}$ ceramics under cyclic stress and resultant fatigue strength at the healing temperature," Journal of the American Ceramic Society, vol. 85, no. 9, pp. 2268-2272, 2002.

[21] K. Ando, K. Furusawa, M. C. Chu, T. Hanagata, K. Tuji, and S. Sato, "Crack-healing behavior under stress of mullite silicon carbide ceramics and the resultant fatigue strength," Journal of the American Ceramic Society, vol. 84, no. 9, pp. 2073-2078, 2001.

[22] K. Takahashi, K. Uchiide, Y. Kimura, W. Nakao, K. Ando, and M. Yokouchi, "Threshold stress for crack healing of mullite reinforced by $\mathrm{SiC}$ whiskers and $\mathrm{SiC}$ particles and resultant fatigue strength at the healing temperature," Journal of the American Ceramic Society, vol. 90, no. 7, pp. 2159-2164, 2007.

[23] W. Nakao, M. Ono, S. K. Lee, K. Takahashi, and K. Ando, "Critical crack-healing condition for $\mathrm{SiC}$ whisker reinforced alumina under stress," Journal of the European Ceramic Society, vol. 25, no. 16, pp. 3649-3655, 2005.

[24] K. Takahashi, Y. S. Jung, Y. Nagoshi, and K. Ando, "Crackhealing behavior of $\mathrm{Si}_{3} \mathrm{~N}_{4} / \mathrm{SiC}$ composite under stress and low oxygen pressure," Materials Science and Engineering A, vol. 527, no. 15 , pp. 3343-3348, 2010.

[25] M. Nakatani, S. Sato, Y. Kobayashi, and K. Ando, "A study on crack-healing + proof test to guarantee the structural integrity of ceramic coil springs," Journal of High Pressure Institute of Japan, vol. 43, no. 2, pp. 85-91, 2005.

[26] M. Ono, W. Nakao, K. Takahashi, M. Nakatani, and K. Ando, "A new methodology to guarantee the structural integrity of $\mathrm{Al}_{2} \mathrm{O}_{3} / \mathrm{SiC}$ composite using crack healing and a proof test," Fatigue \& Fracture of Engineering Materials \& Structures, vol. 30, no. 7, pp. 599-607, 2007. 

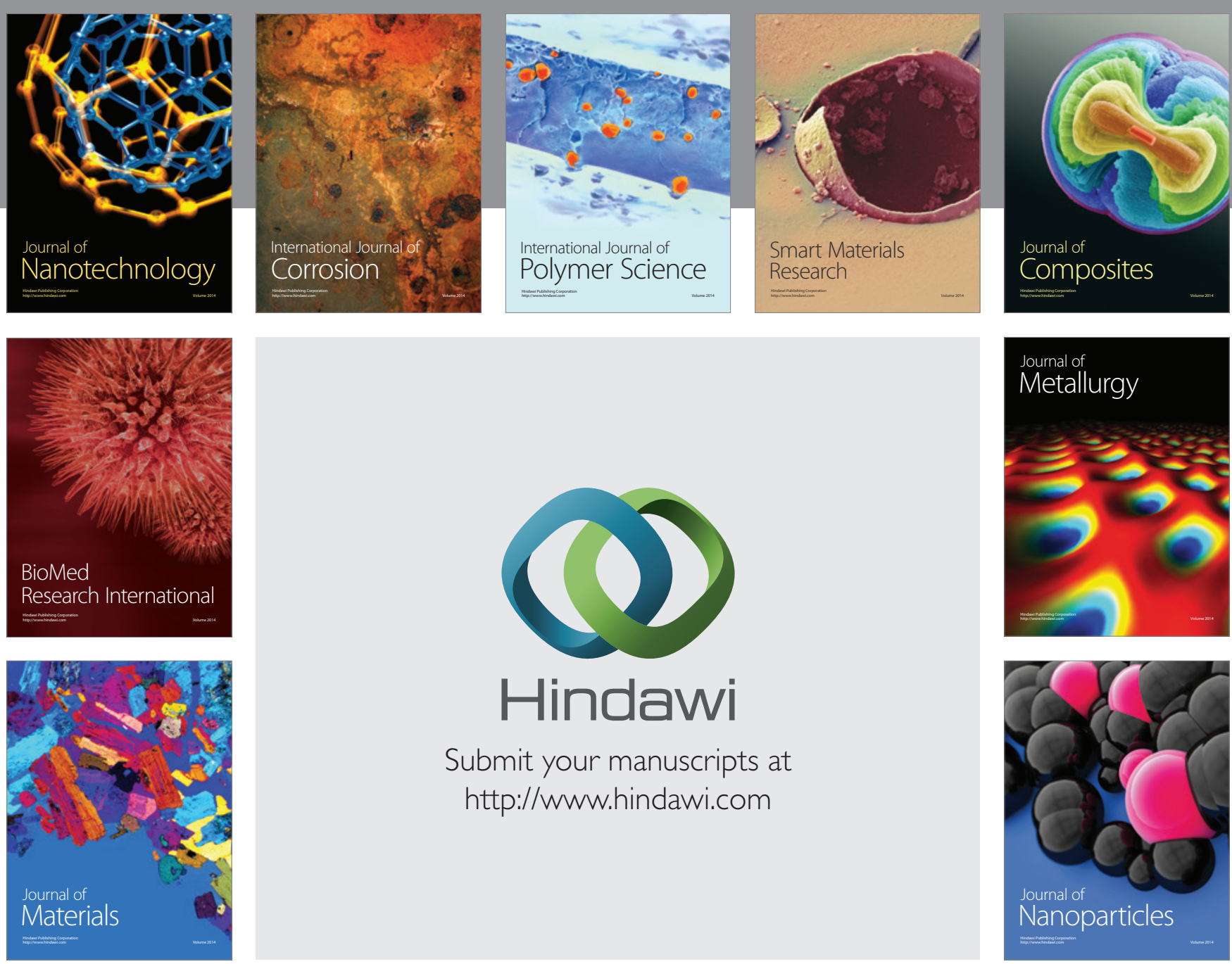

Submit your manuscripts at http://www.hindawi.com
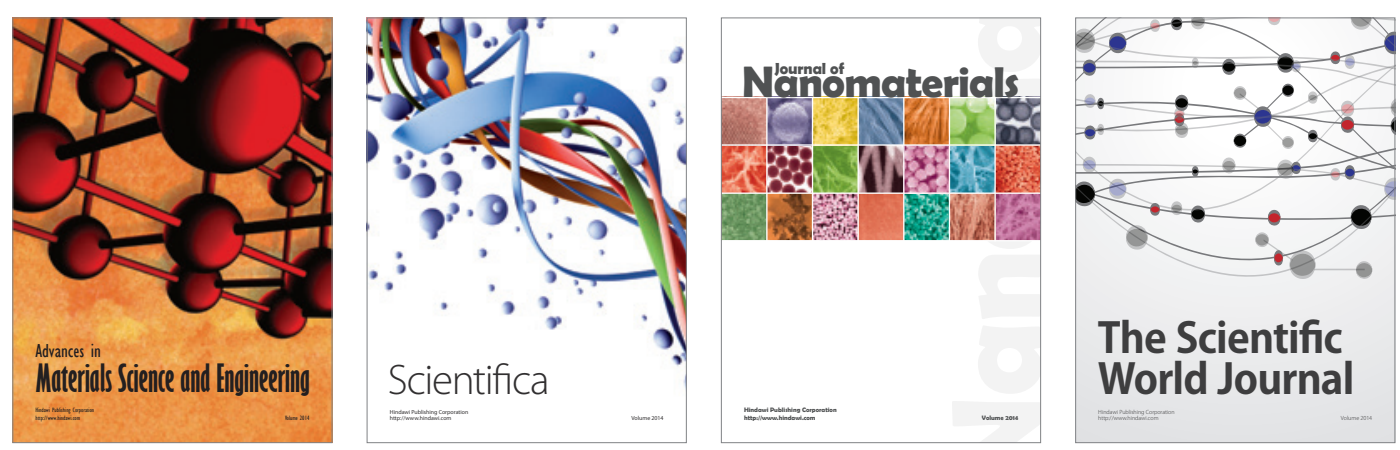

\section{The Scientific World Journal}
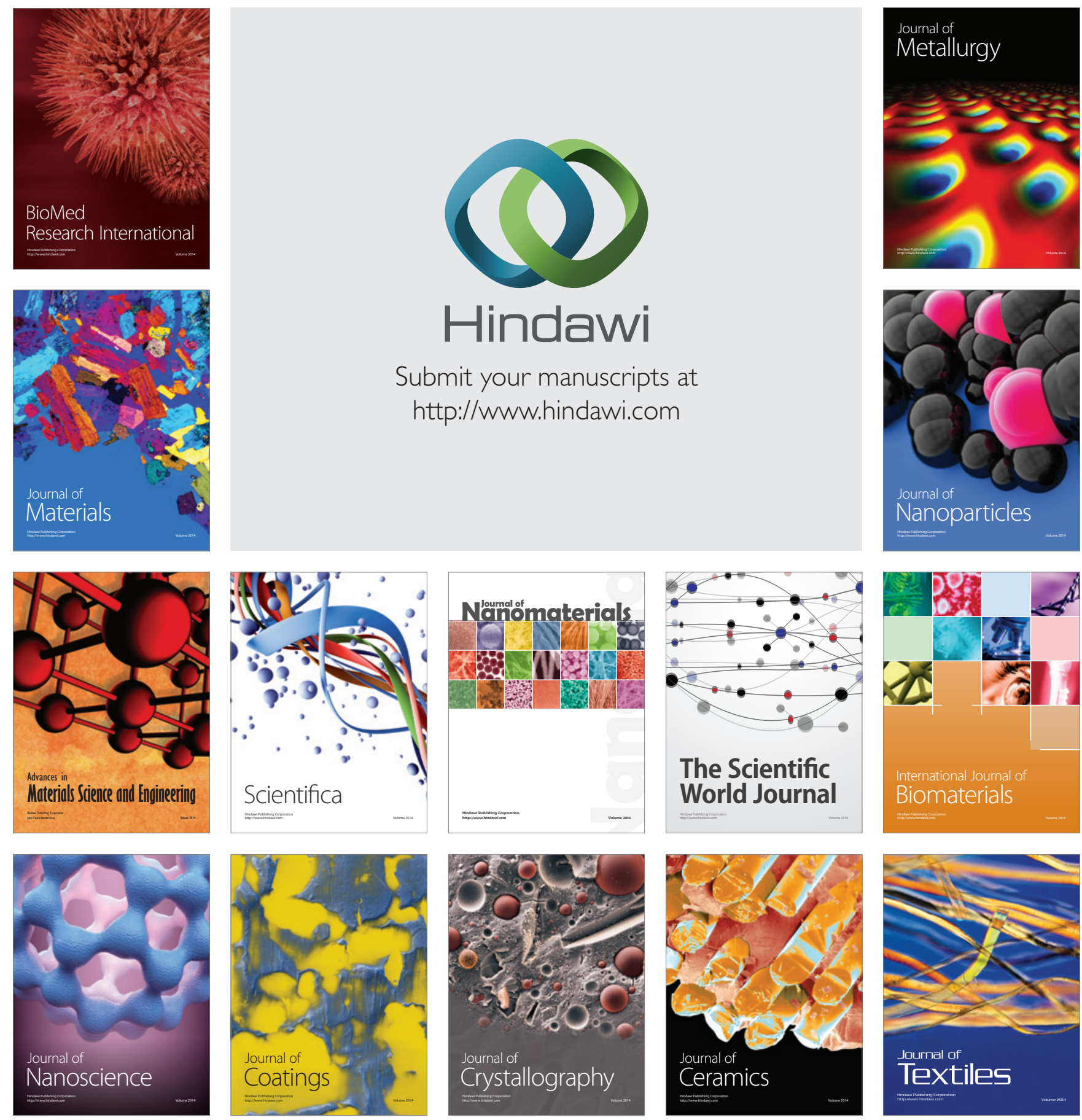